\title{
O TRABALHO NA INDÚSTRIA DE SOFTWARE: a flexibilidade como padrão das formas de contratação
}

\author{
Maria Aparecida Bridi* \\ Mariana Bettega Braunert*
}

\begin{abstract}
O presente trabalho analisa a flexibilidade das formas de contratação da força de trabalho dos desenvolvedores de software de Curitiba e Região e resulta de pesquisa empírica realizada, na qual entrevistamos trabalhadores e empresários do setor. Encontramos a prevalência da contratação de trabalhadores como pessoa jurídica, como "CLT Flex" ou através de cooperativa de trabalho. Além de uma clara tentativa das empresas de afastar os encargos trabalhistas que incidem sobre a relação de trabalho, a proliferação de formas flexíveis de contratação parece estar relacionada, nessa indústria, à forma como se estrutura o processo produtivo, organizado por projetos, e ao discurso justificador das atuais formas de gestão, que têm em seu cerne a noção de empregabilidade. Essas constatações indicam que o trabalho que envolve alta tecnologia também se organiza como um trabalho assalariado tipicamente capitalista, cuja lógica não parece diferir daquela que rege as relações entre capital e trabalho em outros segmentos da economia.

Palavras-chave: Indústria de software. Contrato de trabalho. Flexibilidade. Formas de gestão. Processo produtivo.
\end{abstract}

\section{INTRODUÇÃO}

O presente trabalho é fruto de um projeto de pesquisa integrado desenvolvido por membros do Grupo de Estudos Trabalho e Sociedade (GETS) da Universidade Federal do Paraná (UFPR), denominado "Redes de empresas, trabalho e relações de trabalho no setor de informática no Paraná”. O foco do artigo incide sobre a análise das formas de contratação na indústria de software de Curitiba e Região. O estudo foi motivado, entre outros fatores, pelo destaque que o Estado do Paraná assume na produção de software em nível nacional, pela necessidade de estudar as novas modalidades de trabalho advindas da revolução informacional, bem como pela carência de estudos voltados à análise desse setor na área da Sociologia do Trabalho.

* Socióloga. Doutora em Sociologia. Professora do Departamento de Ciências Sociais (DECISO) e do Programa de Pós-Graduação em Sociologia da UFPR (PPGS).

Rua General Carneiro,460 - $9^{\circ}$ andar - sala 910A, DECISO Centro. Cep: 80060-150 - Curitiba, Paraná - Brasil. macbridi@gmail.com

** Doutoranda em Sociologia do Programa de Pós Graduação em Sociologia (PPGS) da Universidade Federal do Paraná. Pesquisadora do Grupo de Estudos Trabalho e Sociedade (GETS/UFPR).

Alameda Augusto Stellfeld, 1080, ap. 42, Centro, Curitiba/

PR, CEP 80.430-140. mbbraunert@gmail.com
O contexto de nosso objeto se relaciona ao processo de reconfiguração das relações de trabalho, impulsionado pela crise do capital na década de 1970, que desencadeou um processo de reestruturação visando recuperar os padrões de lucratividade habituais pelo capital. Decorrente das transformações técnicas, políticas e econômicas, desde então, emergiu um novo cenário caracterizado pelo aumento crescente do desemprego estrutural, pela desregulamentação e flexibilização das relações do trabalho, a intensificação dos processos de terceirização e de exploração da força de trabalho e precarização das relações de emprego. Esse contexto é marcado, também, pelo fortalecimento da ideologia neoliberal e por um novo modelo de gestão e organização das empresas, distinto do anterior modelo fordista: as práticas, sempre adaptadas para os diferentes países, das modalidades de gestão toyotistas.

De forma imbricada a essas profundas transformações de natureza política, econômica e social, adveio a revolução tecnológica de base microeletrônica que colocou o conhecimento e a informação no centro da "nova economia". Teve como uma de suas consequências o cresci- 
mento do número de profissões que envolvem a produção e o processamento de informações, a exemplo do trabalho de desenvolvimento de software.

Sendo a produção de software emblemática da produção de natureza imaterial, nossa análise problematiza as teorias sobre o trabalho imaterial, tal como elaboradas por Gorz (2005), Lazzarato e Negri (2001), Hardt e Negri (2005). Segundo a perspectiva desses autores, a produção de bens imateriais, desenvolvida no cerne do que eles chamam de "capitalismo cognitivo", seria dotada de um potencial de transformação política, econômica e social, de natureza emancipatória e subversiva. O trabalho ancorado no conhecimento seria, para eles, um trabalho emancipado, de natureza criativa e cooperativa, e impulsionaria a transição da sociedade capitalista para uma outra, de tipo comunista. A leitura dessas teorias nos permitiu elaborar nossas questões de pesquisa, e, em certa medida, contrapor seus postulados a partir da realidade empírica dos trabalhadores estudados, isto é, às suas efetivas condições de trabalho.

Analisamos, no decorrer deste artigo, as condições de trabalho na indústria de software no que concerne, especialmente, às formas de contratação dos trabalhadores do setor. Abordar esse aspecto da relação de trabalho permiN te visualizar uma dimensão do trabalho informacional ignorada pelos teóricos do trabalho imaterial, qual seja: que esse tipo de produção está submetido, como qualquer outro, à lógica de valorização do capital e aos imperativos atuais de flexibilização e de formas precarizadas de relações de trabalho.

Apresentamos, na primeira parte do artigo, uma breve caracterização do setor de desenvolvimento de software, bem como o perfil das empresas e dos trabalhadores que foram objetos deste estudo. Na sequência, esboçamos uma análise sociológica do fenômeno da disseminação e predominância das formas de contratação flexíveis da força de trabalho neste segmento.

\section{CONSIDERAÇÕES SOBRE O SE- TOR DE SOFTWARE, AS EMPRE- SAS E OS TRABALHADORES PES- QUISADOS}

O software se constitui em um conjunto lógico e sistematizado de instruções e informações que comandam o funcionamento de um equipamento informatizado, em oposição à sua parte física, o hardware. É a parte lógica, não tangível, responsável por fornecer instruções sobre o que o hardware (parte física da máquina) deve executar (Diegues Junior, 2010; Cocco; Vilarim, 2009). Sua produção ocorre no setor econômico denominado Tecnologia da Informação (TI's), que, por sua vez, não se reduz ao software, compreendendo, também, todo o conjunto de tecnologias em microeletrônica, incluindo o hardware. Esse setor faz parte da Tecnologia de Informação e Comunicação (TIC), que engloba, também, a telefonia e meios de comunicação, além de equipamentos de escritório, de medição, entre outros (Bridi, 2014). Referirmo-nos a "trabalhadores de TI”, portanto, é muito mais amplo do que falar em "trabalhadores da indústria de software", embora tenhamos identificado no estudo empírico que os trabalhadores dessa área se autodenominam genericamente de "profissionais de TI”, razão pela qual, em alguns momentos, adotamos essa terminologia ao mencionarmos os trabalhadores por nós estudados.

De acordo com Roselino Junior (2006, p. 260), a "indústria" de software comporta “[...] o conjunto de empresas (públicas, nacionais privadas e estrangeiras) que são primariamente voltadas às atividades de desenvolvimento e de comercialização de software [...]", seja na forma de serviços, de software produzido sob encomenda (isto é, desenvolvido para atender à necessidade específica de um cliente) ou comercializado como produto acabado (ou seja, não voltado ao atendimento das necessidades de nenhum usuário particular). Trata-se, como se pode perceber, de um setor bastante heterogêneo, complexo e diversificado, já que ele 
abrange tanto serviços como produtos, e mesmo os produtos são atípicos, pois têm um caráter intangível, semelhante ao dos serviços. (Kubota, 2006).

De acordo com a versão 1.0 da Classificação Nacional de Atividades Econômicas (CNAE 1.0), as empresas voltadas para o desenvolvimento de software e prestação de serviços de TI pertencem à divisão 72 , intitulada "atividades de informática e serviços relacionados”, a qual está incluída na Seção K, que abarca "atividades imobiliárias, aluguéis e serviços prestados às empresas” (SOFTEX, 2009).

Quadro 1 - Divisão 72 da CNAE

\begin{tabular}{|l|c|}
\hline Grupos (6) & \multicolumn{1}{c|}{ Classes (7) } \\
\hline 72.1 - Consultoria em hardware & $\begin{array}{c}7210 \text { - Empresas com atividades em } \\
\text { consultoria em hardware }\end{array}$ \\
\hline 72.2 - Consultoria em software & $\begin{array}{c}7221 \text { - Empresas com atividades em desenvolvimento } \\
\text { e edição de software pronto para uso }\end{array}$ \\
\hline $\begin{array}{c}72.3 \text { - Processamento de dados } \\
72.4 \text { - Atividades de banco de dados e } \\
\text { distribuição online de conteúdo eletrônico }\end{array}$ & $\begin{array}{c}7229 \text { - Desenvolvimento de software sob encomenda e } \\
\text { outras consultorias em software }\end{array}$ \\
\hline $\begin{array}{c}72.5 \text { - Manutenção e reparação de } \\
\text { máquinas de escritório e de informática }\end{array}$ & $\begin{array}{c}7240 \text { - Atividades de banco de dados e distribuição } \\
\text { online de conteúdo eletrônico dados }\end{array}$ \\
\hline $\begin{array}{c}72.6 \text { - Outras atividades de informática } \\
\text { não especificadas anteriormente }\end{array}$ & $\begin{array}{c}7250 \text { - Manutenção e reparação de máquinas de } \\
\text { escritório e de informática }\end{array}$ \\
\hline & $\begin{array}{c}7290 \text { - Outras atividades de informática, não } \\
\text { especificadas anteriormente }\end{array}$ \\
\hline
\end{tabular}

Fonte: Braunert (2013, p. 56). Reelaborado pelas autoras

Observe-se que, para efeito da CNAE, as atividades secundárias das empresas são desconsideradas. Consequência dessa regra é que se perde o registro das atividades de software e serviços de TI desenvolvidas por empresas pertencentes a outras divisões que não a 72 , como é o caso, por exemplo, das atividades de software e serviços de TI realizadas por instituições bancárias, incluídas na divisão 65, intitulada 'intermediação financeira’ (SOFTEX, 2009).

Há, também, um percentual relativamente alto de empresas pertencentes a diferentes divisões do setor industrial que desenvolvem software para embarcar em produto de fabricação própria e/ou melhorar os seus processos. Conforme estudo do Observatório SOFTEX (2009, p. 21) "[...] sabe-se que em outros setores, até mais que na indústria, atividades de software e serviços de TI vêm sendo realizadas por equipes internas [...]”.
Portanto, há profissionais, nessas empresas, empregados em ocupações relacionadas com software e serviços de TI, mas que não pertencem, teoricamente, à indústria de software (isto é, empresas que não pertencem à divisão 72 da CNAE e que não têm como atividade principal o desenvolvimento e a comercialização de software). Como mostra o estudo do Observatório SOFTEX (2009), a quantidade de profissionais com ocupações formais relacionadas com software e serviços de TI (levando em conta as ocupações elencadas pela Classificação Brasileira de Ocupações - CBO) fora da Divisão 72 não é nada desprezível. tudo realizado pelo
Observatório consi-
dera que o setor de
software e serviços
de TI é constituído
tanto pela Indústria
Brasileira de Softwa-
re e Serviços de TI
- IBSS, que inclui
as empresas pertenas empresas pertencentes à divisão 72, quanto pela Não-IBSS (NIBSS), que é composta por todas as demais divisões da CNAE 1.0, entre as quais se encontram as que constituem o setor agropecuário, a indústria, o comércio e os serviços e a administração pública (SOFTEX, 2009; Braunert, 2013).

Em razão da penetração dessa indústria em outras atividades econômicas, optamos pelo estudo empírico focalizado em empresas, de Curitiba e Região, cuja atividade central (e não secundária) consiste na produção de software. A pesquisa de campo envolveu visitas a 7 empresas de desenvolvimento de software de Curitiba e 13 entrevistas com trabalhadores e empresários do setor.

O ponto de partida para chegar a essas empresas foi uma pesquisa no Catálogo de empresas do Arranjo Produtivo Local - APL de software de Curitiba. Analisando as empresas 
da indústria de software do referido Catálogo, identificamos que muitas delas prestavam uma gama bastante ampla de serviços, além do desenvolvimento de software.

Em função disso, priorizamos pesquisar aquelas empresas cuja apresentação colocava como atividade principal o desenvolvimento de soluções em software, preferencialmente que tivessem como atividade básica a produção de software sob encomenda (e não software produto), como podemos acompanhar no Quadro abaixo, que relaciona e caracteriza as empresas pesquisadas e especifica o cargo dos entrevistados:

As empresas pesquisadas são de diferentes portes (pequeno, médio e grande porte). A maioria delas está no mercado há mais de dez anos, sendo, portanto, empresas já consolidadas que prestam serviços para os setores público e privado, em âmbito nacional, sendo que duas delas internacionalmente. Com exceção da Empresa B, cuja atividade-fim principal é a logística e da empresa $\mathrm{H}$, que desenvolve softwares produto, todas as demais têm como atividade principal a produção de software sob encomenda. Produzem serviços de alto valor, que in- cluem todas as etapas do processo de produção do software e envolvem tarefas mais complexas e, frequentemente, conhecimentos específicos de engenharia de software e análise de sistemas. É o tipo de produção que se dá mediante encomendas diretas, em que o cliente determina as especificações do produto, o que leva esse segmento a adquirir características próximas a serviços (Correia; Vasquez; Cario, 2008).

Termos como "gestão", "solução" e "inovação" foram encontrados com frequência nos textos de apresentação dessas e de outras empresas que fazem parte do APL de software. Muitas prestam, além de consultoria em TI, serviços relacionados a "soluções em RH", "central de atendimento", "consultoria de negócios", "gestão empresarial", "solução integrada em gestão" etc., e apresentam-se com a proposta de atender várias demandas dos clientes, com propagandas na seguinte linha: “[...] nos preocupamos com o que é fundamental nas empresas: resultados positivos [...]"; ou "[...] oferecemos soluções para que o cliente seja atendido em suas várias necessidades [...]”.

Como já nos referimos, entrevistamos tre-

Quadro 2 - Caracterização das empresas estudadas e funções dos entrevistados

\begin{tabular}{|c|c|c|}
\hline Empresa & Caracterização & Entrevistado \\
\hline Empresa A & $\begin{array}{l}\text { Empresa de grande porte que atua no setor público e privado há mais de } 20 \\
\text { anos. Entre outros serviços, desenvolve software sob encomenda, e dispõe, } \\
\text { para tanto, de uma Fábrica de software. }\end{array}$ & $\begin{array}{c}\text { Gerente de } \\
\text { desenvolvimento }\end{array}$ \\
\hline Empresa B & $\begin{array}{l}\text { Empresa internacional de grande porte. Atua na área de logística há mais de } \\
10 \text { anos e possui um grande número de profissionais atuando no setor de } \\
\text { Tecnologia da Informação, embora o desenvolvimento de software não seja } \\
\text { a atividade-fim da empresa. }\end{array}$ & - \\
\hline Empresa C & $\begin{array}{l}\text { Empresa familiar de pequeno porte. Desenvolve software sob encomenda e } \\
\text { licencia produtos. }\end{array}$ & Diretor \\
\hline Empresa D & $\begin{array}{l}\text { Localizada no Parque de Software e há cerca de } 15 \text { anos no mercado, } \\
\text { desenvolve software sob encomenda. }\end{array}$ & $\begin{array}{l}\text { Responsável pela } \\
\text { área de Recursos } \\
\text { Humanos }\end{array}$ \\
\hline Empresa E & $\begin{array}{l}\text { Há mais de } 20 \text { anos no mercado, a empresa desenvolve software sob } \\
\text { encomenda e atende, principalmente, o setor público. Para tanto, conta com } \\
\text { uma fábrica desoftware e uma equipe de cerca de } 200 \text { funcionários. }\end{array}$ & Diretor comercial \\
\hline Empresa F & $\begin{array}{l}\text { Empresa de grande porte e há cerca de } 20 \text { anos no mercado, produz } \\
\text { softwares customizados, isto é, direcionados às demandas dos clientes, e } \\
\text { atua em nível internacional. }\end{array}$ & $\begin{array}{l}\text { Coordenadora de } \\
\text { gestão / Analista de } \\
\text { processos }\end{array}$ \\
\hline Empresa G & $\begin{array}{l}\text { Empresa de pequeno porte, especializada na produção e licenciamento de } \\
\text { softwarede gestão de qualidade. }\end{array}$ & Gerente \\
\hline Empresa $\mathrm{H}$ & $\begin{array}{l}\text { Empresa de pequeno porte, desenvolve três tipos desoftwares produtos e } \\
\text { atende a demandas do setor privado. }\end{array}$ & Sócio \\
\hline
\end{tabular}


ze trabalhadores, sendo que seis eram analistas de sistemas e dois programadores. Os demais entrevistados (uma entrevista para cada função) realizavam as atividades como analista-programador, analista de suporte, arquiteto de software, engenheiro de software e gerente de TI.

Os profissionais entrevistados configuram-se, em sua maioria, como homens, jovens e com curso superior. São autodidatas e buscam atualizarem-se constantemente para atender às exigências de um mercado de trabalho dinâmico. As certificações técnicas são valorizadas e, por isso, são frequentemente buscadas por eles. Em termos de competências, devem ser dinâmicos, comunicativos e ter capacidade de trabalhar em equipe, além de dispor de uma boa rede de relacionamentos.

Quando analisamos o processo de desenvolvimento de software, observamos que se trata de atividade complexa e muito marcada pela participação ativa do cliente. Ocorre em etapas, e, quando realizado em equipes (maioria dos casos dessa amostra), a partir de uma divisão das tarefas, pois cada profissional desempenha um papel bem definido no processo de produção. Em termos gerais, há processos como os de codificação (programação) que se tornam repetitivos e automáticos. As empresas de software tendem a incorporar aspectos do toyotismo à medida que suas atividades são realizadas em equipes, com níveis hierárquicos reduzidos, requerendo trabalhadores flexíveis, polivalentes, multifuncionais e pautados por metodologias de certificação de qualidade (CQC's). O ritmo intensificado, que ocorre, principalmente, no momento da finalização dos projetos e de elevadas demandas, acarreta desgaste, sobretudo mental, aos trabalhadores.

\section{A FLEXIBILIZAÇÃO DAS RELA- ÇÕES DE TRABALHO NA INDÚS- TRIA DE SOFTWARE}

A flexibilização surgiu como uma das estratégias adotadas pelo capital para manter seu ciclo de acumulação face à crise econômica pela qual passou na década de 1970. Ela afeta várias dimensões da relação de trabalho e pode ser entendida como uma "liberdade" da empresa para determinar, unilateralmente, as condições de uso da força de trabalho, ajustando a jornada, a remuneração e as formas de contratação às flutuações econômicas, desregulando ou adaptando a proteção trabalhista às condições do mercado (Antunes, 2009; Krein, 2001).

Vislumbra-se, nesse cenário, uma crescente flexibilização das formas de contratação da força de trabalho, tendência da qual a indústria de software parece ser emblemática, como vem mostrando alguns estudos sobre o setor (Salatti, 2005; Oliveira, 2009). Na pesquisa por nós realizada com os trabalhadores da indústria de software localizadas em Curitiba e Região (PR), também identificamos uma grande variedade de formas de contratação. Para essas formas de contratação encontradas, utilizamos a expressão "CLT" para designar os trabalhadores contratados pelas normas da Consolidação das Leis do Trabalho e "PJ" para os que se constituem como Pessoa Jurídica (empresa individual) e, nessa qualidade, prestam serviço para a contratante. Os trabalhadores cooperados são contratados através de cooperativas de trabalho e o chamado "CLT Flex", indica, por sua vez, que, embora tenham o contrato de trabalho regido pelas leis trabalhistas, apenas parcela da remuneração é registrada na carteira de trabalho.

Entre os trabalhadores por nós entrevistados, 5 (cinco) são contratados através da CLT, 2 (dois) através de cooperativa e 6 (seis) prestam serviço como pessoa jurídica (PJ), sendo que a maioria destes já trabalhou como celetista em algum momento da sua carreira. A pesquisa mostra, ainda, uma presença marcante da forma contratual denominada "CLT Flex", que será analisada de forma mais detalhada posteriormente. Apenas 2 (dois) entre os 13 (treze) trabalhadores que entrevistamos sempre foram contratados integralmente pela CLT. 
É o que ilustra o Quadro abaixo, no qual consta a atual forma de contratação dos trabalhadores e as espécies de vínculos a que já estiveram submetidos no decorrer de sua trajetória. nação de PJ no setor - é por nós interpretado como se tratando, na maioria das vezes, de uma estratégia utilizada pelas empresas para "contratar" força de trabalho a baixo custo, que
Quadro 3 - Função e formas de contratação (atuais e anteriores) dos trabalhadores

\begin{tabular}{|lccc|}
\hline Trabalhador & Função & Vínculos anteriores & Vínculo atual \\
\hline Trabalhador 1 & Analista de sistemas & PJ e CLT Flex & CLT \\
\hline Trabalhador 2 & Analista de sistemas & CLT & PJ \\
\hline Trabalhador 3 & Analista de sistemas & CLT & PJ \\
\hline Trabalhador 4 & Programador & CLT & CLT \\
\hline Trabalhador 5 & Arquiteto de software & CLT Flex & CLT \\
\hline Trabalhador 6 & Analista de sistemas & CLT & PJ \\
\hline Trabalhador 7 & Engenheiro de software & CLT & PJ \\
\hline Trabalhador 8 & Programador & CLT Flex & PJ \\
\hline Trabalhador 9 & Analista de sistemas & CLT & PJ \\
\hline Trabalhador 10 & Analista-programador & CLT & CLT \\
\hline Trabalhador 11 & Gerente de TI & CLT & Cooperativa \\
\hline Trabalhador 12 & Analista de sistemas & CLT e PJ & Cooperativa \\
\hline Trabalhador 13 & Analista de suporte & Autônomo & CLT \\
\hline
\end{tabular}

Fonte: Braunert (2013, p. 108)

O Quadro revela a variedade de formas de contratação a que estão submetidos os entrevistados. A maioria deles já trabalhou em algum momento da carreira contratado pelas normas da CLT (mesmo os que atuam hoje como prestadores de serviço). Essa situação se altera, entretanto, quando vistos os vínculos atuais, que, em sua maioria, estão sob forma contratual flexível: PJ e cooperativa. Sinaliza,

s portanto, uma mudança na condição desses సิ trabalhadores: de celetista passaram a ser PJ e ou cooperativado.

Como mostra o Quadro 3, 6 (seis) dos 13 (treze) trabalhadores entrevistados prestam $\underset{\circlearrowleft}{\vec{\gamma}}$ serviço para as empresas da indústria de sofI tware como pessoa jurídica (PJ). Corrobora com $\curvearrowright$ esse estudo, a pesquisa de Salatti (2005), que \& encontrou $36 \%$ de trabalhadores de sua amos๙ tra atuando sob essa forma contratual. Também

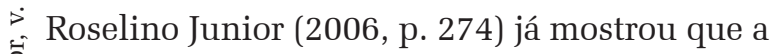
contratação de trabalhadores por meio de empresas constituídas como pessoa jurídica tende a ser predominante no setor de TI em relação às contratações amparadas pela CLT.

O "pejotismo" - como costuma ser designado o fenômeno de crescimento e dissemi- tem se difundido amplamente no país, especialmente no setor de TI. O trabalhador PJ, do ponto de vista fático, é um trabalhador como outro qualquer, ou, nos termos de Carvalho (2013), um "trabalhador-empresa", como veremos adiante, pois realiza as atividades para a empresa contratante e de forma subordinada. Exerce suas atividades em empresas, como observam Galeazzi e Holzmann (2011, p. 264)

[...] submetendo-se às regras e imposições do trabalho subordinado, mas não sendo contratado como empregado. Deve, nessa condição, responsabilizar-se pela regularização burocrática de sua "empresa" e das despesas daí decorrentes, além de prover suas próprias garantias previdenciárias e outras precauções que lhe deem segurança frente a imprevistos eventuais.

De acordo com Pereira (2013, p. 110)

[...] é uma modalidade de vínculo flexível que não garante os direitos trabalhistas e previdenciários para o trabalhador, porém que encontra formalização através do enquadramento de Microempreendedor Individual (MEI) e Microempresa Simples modalidades com tributos fiscais reduzidos criadas pelo Estado com o intuito de reduzir o desemprego e a informalidade que assolavam o Brasil no decorrer da década de 1990.

Segundo Dedecca (2009, p. 138), a disseminação do "pejotismo" indica que "[...] a relação de subordinação do trabalho ao capital passou a ser, muitas vezes, regida por contrato de prestação de serviços, no qual o trabalhador se constituía como pessoa jurídica [...]”. O autor ressalta que, à medida que o trabalhador se constitui em uma empresa, dele é retirada toda a proteção social ao seu trabalho, com o que se 
estabelece uma nova forma de contrato de trabalho sem proteção social específica, mas totalmente enquadrada nas determinações legais. Encontramos essa modalidade de contratação da força de trabalho em praticamente todas as empresas por nós estudadas; além disso, analisando os dados do Quadro 1 percebe-se que um expressivo número de profissionais que já trabalhou como celetista, hoje possui vínculo como pessoa jurídica com a empresa para a qual presta serviço. O "pejotismo", ademais, é um fenômeno que independe da função que o trabalhador exerce na empresa, pois encontramos tanto programadores quando analistas e arquitetos de software trabalhando sob essa modalidade contratual.

Além da contratação de trabalhadores como pessoa jurídica, a contratação por cooperativas profissionais também parece ser um fenômeno comum na indústria de software. Embora tenhamos encontrado 2 (dois) trabalhadores contratados por intermédio de cooperativas de trabalho em um total de 13 (treze) entrevistados, as informações obtidas nas entrevistas e sobre o setor corroboram com essa tese.

As cooperativas profissionais são um fenômeno semelhante ao "pejotismo", no sentido de que vêm se constituindo, atualmente, em uma estratégia de contratar força de trabalho sem arcar com os encargos trabalhistas decorrentes. Muitas cooperativas funcionam, na prática, como um mecanismo de flexibilização da força de trabalho, ou seja, como meras cooperativas de "fachada", organizadas sem respeitar características essenciais do cooperativismo, servindo como mera intermediação de força de trabalho. De acordo com Pinto e Kemmelmeier (2011), utiliza-se uma simulação de cooperativismo para burlar e afastar a incidência do Direito do Trabalho, já que estabelecem mecanismos jurídicos que permitem a contratação de força de trabalho fora dos moldes clássicos do contrato de trabalho. É o que observa também Neves (2011, p. 444): “[...] muitas cooperativas se organizam como cooperativas de intermediação de mão-de-obra, especializadas em processos de terceirização que objetivam diminuir o custo da mão-de-obra e a liberação dos encargos trabalhistas".

Druck e Franco (2009) analisam que o cooperativismo retira toda a proteção social garantida pelo assalariamento, ou seja,

[...] os trabalhadores são cooperativados e, nesta condição, não são assalariados, o que lhes retira a proteção social do Estado, já que, teoricamente, eles estariam se 'autogerindo' e, assim, se 'auto-protegendo”' (Druck; Franco, 2009, p. 235).

Por essa razão, as autoras consideram as cooperativas a forma de terceirização mais perversa que se difundiu nessa década, pois elas precarizam o trabalho de forma legal, isto é, coberta pela legislação. Essa análise vale, também, para o caso de Pessoas Jurídicas.

O contrato de trabalho denominado de "CLT Flex" constitui, também, uma forma típica de contratação no setor de produção de software. Vários empresários e trabalhadores afirmam ser essa uma prática comum no setor de TI, e 3 (três) dos nossos entrevistados já tinham, no decorrer de suas trajetórias profissionais, estabelecido relação de trabalho nessa modalidade contratual. Entre esses três profissionais, temos um Analista de Sistemas, um Arquiteto de Software e um Programador, o que indica que a utilização dessa forma de contratação independe da função que o trabalhador exerce na empresa, igualmente ao que ocorre com o "pejotismo".

O denominado "CLT Flex" corresponde a uma prática antiga e bastante conhecida, por ser utilizada em grande escala, por exemplo, no caso do trabalho doméstico: o trabalhador é contratado pelas normas da CLT, ou seja, com registro na Carteira de Trabalho (CTPS); porém, apenas parte da remuneração é "declarada", sendo o restante pago "por fora". O que nos chamou a atenção é a naturalidade com que trabalhadores e empresários da indústria de software se referem a essa prática, o que nos leva a considerar que se trata de algo recorrente e institucionalizado no setor. 


\section{FLEXIBILIDADE CONTRATUAL NA INDÚSTRIA DE TI: algumas refle- xões sociológicas}

Percebe-se que o setor de produção de software caracteriza-se pela utilização de uma série de formas flexíveis de contratação, principalmente o "pejotismo", o trabalho cooperado e o "CLT Flex". Na tentativa de compreender o fenômeno sociologicamente, nosso estudo apontou três fatores que parecem explicar, de forma contundente, o fenômeno: i) o intuito de burlar a legislação trabalhista, para que as empresas, livres dos encargos sociais que incidem sobre a relação de trabalho, mantenham a competitividade no mercado globalizado; ii) a adequação dos contratos flexíveis de trabalho à forma como se organiza o processo produtivo de desenvolvimento de software, realizado por projetos; e iii) a adesão dos trabalhadores ao discurso das atuais formas de gestão, que tem em seu cerne noções como as de risco, individualismo e empregabilidade.

Ao analisar o trabalho dos desenvolvedores de software em diversas empresas de Curitiba e Região (PR), percebemos que esses trabalhadores recebem um tratamento bastante semelhante dentro das empresas, independente da forma pela qual são formalmente 을 Contratados. A igualdade de tratamento que o ণ prestador de serviço (o PJ) e o trabalhador celetista recebem dentro da empresa sinaliza que สี่ a utilização de mecanismos mais flexíveis de contratação da força de trabalho constitui uma S. estratégia para afastar a incidência dos encar¿ gos sociais da relação de trabalho, já que, na § prática, as condições e a gestão do trabalho são $\dot{A}$ as mesmas independente do contrato formal $\stackrel{\infty}{\sim}$ de trabalho.

Isso se evidencia quando os trabalhadores que atuam como prestadores de serviço recorrem à Justiça do Trabalho pleiteando reconhecimento do vínculo de emprego. Eles costumam ser contemplados em suas reivindicações, caso reste comprovado que o trabalho era prestado de forma pessoal, não eventual, subordinada e remunerada, caracterizando-se, assim, a existência de uma relação de emprego disfarçada. Baltar, Krein e Leone (2009, p. 40) mostram que, segundo a legislação brasileira,

[...] a relação de emprego disfarçada ocorre quando estão presentes as características do trabalho assalariado, mas a contratação da prestação do serviço é feita sem contemplar os direitos trabalhistas e previdenciários a ele vinculados. Ou seja, está contida uma relação de subordinação do trabalho, mas a forma de contratação não é dada por um contrato regular portanto, trata-se de uma simulação.

Cardoso (2003) analisa os fenômenos do crescimento da ilegalidade e, consequentemente, das reclamatórias trabalhistas, cuja demanda central é o reconhecimento do vínculo empregatício, como uma deslegitimação e contestação do direito do trabalho, que, historicamente, regula a exploração da força de trabalho, perante o empresariado. Segundo o autor, "[...] os capitais se sentem, crescentemente, desobrigados, flexibilizando a frio o mercado de trabalho [...]" e, dessa forma, cobrindo-o com o manto da ilegalidade (Cardoso, 2003, p. 159160). Essa ilegalidade, para Cardoso (2003), não é outra coisa senão a versão mais crua da luta de classes, já que, ao invés de buscar interferir nos processos legislativos para que sejam produzidas leis que os favoreçam, os capitalistas passaram a atuar no mercado de trabalho, recusando-se a acatar a ordem legal.

O depoimento do Gerente de Desenvolvimento de uma das empresas por nós estudadas, aqui denominada de Empresa A, corrobora essa tese. Segundo ele, a utilização indiscriminada de formas flexíveis de contratação na indústria de software ocorre porque os encargos trabalhistas são muito altos, a legislação trabalhista é rígida e isso inviabiliza a competitividade das empresas. De acordo com o entrevistado, esse fator dificulta a contratação de profissionais pelo “CLT Full”, que, em oposição ao "flex”, é aquele em que o empregado tem registrado na carteira de trabalho o valor integral dos seus ganhos salariais (Braunert, 2013), e, consequentemente, tem todos os direitos trabalhistas assegurados:O CLT-FULL é muito complicado, não dá competitividade na hora de contratar, sabe? Não é bom pra ninguém, na verdade. Só é bom Para o governo, né? Não é bom pro salário, 
não é bom pro cara, não é bom pra empresa. Porque tem encargos e a empresa quer e pode pagar mais, como assim o faz, se for PJ. Mas não consegue, porque tá amarrada nas questões dos impostos e tal, daí não dá competitividade, porque o concorrente paga de forma diferenciada, né? E não tem como! Em São Paulo, então, é próximo do impossível o cara ser CLT. Eu não conheço ninguém lá em São Paulo, do meu relacionamento, que seja CLT, com tudo certinho, assim. Em São Paulo é bem mais agressivo, bem mais agressivo. Os caras pagam pelo diferencial mesmo. A média de salário em São Paulo é, dependendo do cargo, quase chega a ser o dobro daqui. Então, na minha opinião o CLT, cara... putz, é duro, viu? (Entrevista n ${ }^{\circ}$ 1, realizada com o Gerente de desenvolvimento da Empresa A, em abril de 2012).

Sabe-se, entretanto, que esse argumento de que a legislação do trabalho, no Brasil, é muito rígida, não se comprova pela realidade do mercado e das relações de trabalho nos anos 1990, como mostra Krein (2001). Para o autor, o desafio aqui é o contrário: aumentar a formalização e criar estruturas sociais mais homogêneas, o que só ocorrerá com um grau maior de regulação social.

Segundo Cardoso (2003, p 89), estudos produzidos por instituições oficiais mostram que o mercado de trabalho brasileiro já é um dos mais flexíveis do mundo. Nas palavras do autor, “[...] o mercado de trabalho por aqui se marca [...] por enorme flexibilidade alocativa e salarial, o que dá inteira liberdade aos capitais produtivos em momentos de choque econômico como o que estamos analisando".

A variedade de formas de contratação existentes na indústria de software de Curitiba e Região parece estar ligada, assim, a uma estratégia do capital para burlar a legislação trabalhista e afastar a incidência dos encargos sociais sobre a relação de trabalho.

Além disso, a pesquisa por nós realizada indica que a flexibilidade das formas de contratação está relacionada, nessa indústria, à própria dinâmica do processo produtivo tal como ele é organizado (qual seja, através do desenvolvimento de projetos que atendam a demandas específicas dos clientes). Isso porque o processo de produção de software "sob encomenda" é realizado por etapas e iniciase com uma solicitação específica do cliente, cabendo à empresa oferecer a solução tecnológica para a demanda apresentada. Assinado o contrato de prestação de serviços, o gerente de projetos monta a equipe necessária para o desenvolvimento do software e distribui as atividades, sendo que o número de trabalhadores que compõe essa equipe varia de acordo com o tamanho do projeto e o prazo acordado com o cliente.

Essa estruturação do processo de trabalho acaba por interferir na alta rotatividade e flexibilidade de contratação de força de trabalho na indústria de software, já que os profissionais são contratados "por projetos", ou seja, para trabalhar alocados em projetos específicos que a empresa está desenvolvendo no momento.

Isso significa que as empresas recrutam profissionais de TI conforme as necessidades conjunturais, isto é, a demanda de trabalho. Embora a maioria tenha informado que procura realocar os trabalhadores em outros projetos quando finda aquele a que o trabalhador estava inicialmente vinculado, nem sempre isso é possível. Segundo o depoimento do Diretor de uma das empresas pesquisadas, as empresas têm uma visão focada no resultado e não fazem um esforço para manter uma equipe permanente.

A grande maioria das empresas maiores não querem saber se o cara tá há um bom tempo ou não tá. Eles querem saber o custo. Se o custo não tá legal, acabou o projeto, manda embora mesmo. Então também tem isso: muitas empresas mandam embora por qualquer coisa e depois contratam por qualquer coisa, eles não tentam manter a equipe. Fica muito a visão de só o resultado (Entrevista $\mathrm{n}^{\circ} 2$, realizada com o Diretor da Empresa C, em abril de 2012).

O gerente de desenvolvimento da Empresa A destacou, também, que os profissionais trabalham alocados em projetos específicos, e, quando finalizados, costumam ser realocados em outros projetos. Ele afirmou que, eventualmente, não há um número suficiente de projetos para todos os profissionais e alguns pre- 
cisam ser dispensados, mas essa não é a regra, já que a área comercial da empresa costuma "conseguir" sempre muitos projetos. Outra entrevistada, a Coordenadora de gestão da Empresa F, informou, também, que lá se constituem equipes de trabalhadores por projetos, e que, findo o projeto, procura-se realocar os profissionais em outros projetos que estejam iniciando. Afirmou, ainda, que o tempo médio que o trabalhador permanece na empresa é de 2 a 3 anos (Entrevista $\mathrm{n}^{\circ} 5$, realizada com a Coordenadora de gestão da empresa F, em março de 2012).

A estratégia de contratar profissionais de acordo com as necessidades conjunturais da empresa consiste em uma tendência dos mercados de trabalho, que é reduzir o número de trabalhadores "centrais" ou diretos e empregar, cada vez mais, uma força de trabalho que entra facilmente no mercado e é demitida sem custos quando não há demanda que justifique sua permanência (trabalhadores flexíveis), nos termos de Harvey (1993).

A tendência crescente à flexibilidade apontada por Harvey resultou da adoção de um novo paradigma de produção e gestão da força de trabalho, o toyotismo, idealizado pelo engenheiro Taiichi Ohno e introduzido na fábrica da Toyota, no Japão. Tendo como característica central a organização just-in-time, na qual a เ2 produção é orientada pela demanda do mercaธิ do, a empresa toyotista é organizada, também, 客 de maneira enxuta e flexível, empregando um “pessoal mínimo" ou "efetivo mínimo que ocup pa lugares-chave” (Coriat, 1994, p. 34), e mobi今. lizando o restante da força de trabalho de acordo com as demandas concretas do mercado.

Assim, em razão da rapidez das inova\& ções tecnológicas e da instabilidade do meri cado, as empresas tendem a contratar a força

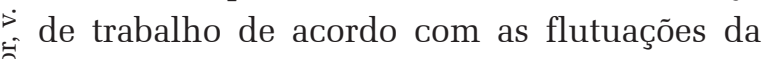
demanda: "[...] no interior das empresas, a flexibilidade traduz-se na variação do número de trabalhadores, cujos aumentos ou reduções vão sendo adequados às necessidades da produção” (Holzmann e Piccinini, 2011, p. 197). E, para o caso do trabalho por projetos, típicos no setor de software, essa lógica se faz ainda mais presente.

Como observa Kovács (2004, p. 34), a difusão de formas de emprego flexíveis pode implicar um forte crescimento de uma força de trabalho fluida que pode ser contratada, despedida, externalizada, de acordo com as necessidades de adaptação ao mercado por parte das empresas.

Com isso, tem-se uma dualização dos trabalhadores, pois, de um lado concentra-se o chamado "núcleo duro", ou seja, aqueles que dispõem de um contrato de trabalho por tempo indeterminado, com carreiras asseguradas e direitos garantidos e, de outro, os "assalariados da precariedade”, com futuro profissional incerto (Oliveira; Carvalho, 2008).

O relato do diretor comercial da Empresa E deixa claro que esse fenômeno se confirma na realidade por nós estudada, pois, segundo ele, a empresa procura manter alguns "elementos-chave" em seu quadro permanente, sendo que o restante da força de trabalho é contratado de acordo com as necessidades, isto é, conforme os projetos forem "aparecendo".

O que a empresa tem que fazer é ter a consciência de que ela precisa manter alguns elementos-chave. [...] Você tem que tentar manter (isso depende do porte da empresa, né?) uns dois ou três bons gerentes de projeto, um ou dois especialistas em qualidade de software, um arquiteto de sistemas, que é a pessoa que faz as fundações do sistema, um bom cara de banco de dados, que é a pessoa que cuida que o sistema seja bem organizado. Você tem que pegar os elementos-chave e manter e o resto quando você vai assumir um projeto novo você tem que ver a viabilidade de cumprir naquele prazo e como você corre pra estruturar a tua equipe (Entrevista $n^{\circ} 4$, realizada com Diretor comercial da Empresa E, em abril de 2011).

Os trabalhadores parecem também reconhecer a fluidez do mercado e a vulnerabilidade a que estão permanentemente submetidos. Um dos trabalhadores entrevistados, Analista de sistemas da Empresa C, afirmou que, enquanto dura o projeto, os trabalhadores têm uma renda garantida, mas assevera que a estabilidade, hoje, é algo complicado, pois ela é por projeto, 
por contrato. Segundo ele, é importante que os trabalhadores tenham consciência de que a garantia que eles têm é o período de duração do projeto em que estão trabalhando.

Às vezes a empresa tem um projeto grande, que de-
manda 10 profissionais mas de repente termina o
projeto. O que que você vai fazer com aquela mão-de
-obra? Então, enquanto dura o projeto você tem uma
renda e uma garantia. Então, a estabilidade hoje é
muito complicada. Ela é por projeto, ela é por contra-
to, né. Então a empresa tem um contrato, mesmo que
a médio prazo, um contrato de 2 , 3 , anos pra desen-
volver um projeto. Esse é o teu período. Tem que ter
consciência de que tua garantia é essa. (Entrevista
$n^{0} 19$, realizada com o Trabalhador 12, Analista de
sistemas da Empresa C, em abril de 2012).

Conforme mostra o relato acima transcrito, o emprego estável não parece, de fato, fazer mais parte do "horizonte existencial" dos trabalhadores, ao menos no setor de produção de software, já que eles se mostram conscientes da instabilidade e vulnerabilidade da condição contratual a que estão submetidos.

Esses assalariados da precariedade (no caso, aqueles que são facilmente contratados e demitidos pelas empresas) são mais vulneráveis, porque dispõem de um conjunto menor de direitos e proteções. Como analisa Graça Druck “[...] é o tempo de novos (des)empregados, de homens empregáveis no curto prazo, através das (novas) e precárias formas de contrato [...]" (Druck, 2011, p. 43).

Observamos, assim, que as empresas pesquisadas que desenvolvem software sob encomenda em Curitiba e Região adotam, claramente, uma estratégia típica do capital nos dias atuais, que é a flexibilidade em recrutar e demitir funcionários de acordo com as necessidades conjunturais da empresa. Essa tendência, que está presente em diversos setores econômicos, parece assumir uma grande funcionalidade no processo produtivo de softwa$r e$, cuja organização é estruturada por projeto.

Percebe-se, por fim, que os trabalhadores envolvidos na produção de software parecem absorver o discurso das atuais formas de gestão, que, tendo como elemento central o conceito de empregabilidade, corrobora com a aceitação das formas flexíveis de contratação pelos assalariados. É bastante comum eles afirmarem que "cada um faz sua estabilidade" apresentando um bom trabalho, como mostram os relatos abaixo.

\begin{abstract}
Mais estabilidade está em você procurar apresentar um bom trabalho e você... vamos dizer assim, quem está te contratando vê que você é importante no meio. Você apresenta um bom trabalho: isso eu acho que é estabilidade. É o trabalho bem feito. (Entrevista $\mathrm{n}^{\circ} 8$, realizada com o Trabalhador 1, Analista de sistemas da Empresa A, em abril de 2012).

O que eu vejo hoje que estabilidade não é um problema. Para aqueles que fazem certo as coisas estabilidade não é um problema. Até porque as empresas tão vendo que o mercado tá ruim pra você contratar, então é melhor você valorizar o que você tem do que ter que sair a busca de outro. (Entrevista $\mathrm{n}^{\mathrm{o}} 14$, realizada com o Trabalhador 7, Engenheiro de software da Empresa B, em abril de 2012).
\end{abstract}

Outro trabalhador afirmou que, se um empregado "trabalha bem", ele faz a sua estabilidade, independente da idade:

Estabilidade? Eu acho que se você trabalha bem você faz a estabilidade, né, então se você não importa se você for uma empresa ou for uma pessoa só, se você trabalha bem e tem comprometimento eu acho que você sempre vai ser estável, não importa nem a idade. Ainda mais nessa área que não precisa de esforço físico... eu acho que se você não para no tempo você consegue essa estabilidade. Então nisso eu não tenho medo, né, se você tá sempre correndo atrás você sempre tá no mercado (Entrevista $n^{\circ} 10$, realizada com o Trabalhador 3, Analista de sistemas da Empresa A, em abril de 2012).

Parece-nos, assim, que os trabalhadores da indústria de software tendem a assumir o discurso da gestão empresarial que busca obter a colaboração dos assalariados para a obtenção do lucro capitalista. Segundo Boltanski e Chiapello (2009, p. 239), esse discurso está ligado ao desenvolvimento de um projeto que se vincula ao culto do desempenho individual e à exaltação da mobilidade. Na análise das autoras, “[...] a apologia da mudança, do risco e da mobili- 
dade substitui então a valorização da ideia de garantia” (Boltanski; Chiapello 2009, p. 121).

A análise de Harvey (1993) também ajuda a compreender o fenômeno, pois, de acordo com o autor, houve uma alteração das normas e dos valores coletivos que tinham hegemonia nos anos 1950 e 1960, e evolui-se para um individualismo muito mais competitivo como valor central numa nova cultura empreendimentista que penetrou em muitos aspectos da vida. Lembra, ainda, o autor que, nesse novo contexto, a ação coletiva se tornou mais difícil e "[...] o individualismo exacerbado se encaixa no quadro geral como condição necessária, embora não suficiente, da transição do fordismo para a acumulação flexível” (Harvey, 1993, p. 161).

A noção de "empregabilidade" parece ser um elemento-chave desse discurso. Como já apontou Cardoso (2003), ela constitui a outra face da dinâmica da desregulamentação do trabalho, pois transfere ao empregado a responsabilidade, não só de encontrar um emprego para si, como, também, de manter-se no emprego. Como analisa Krein (2011, p. 248), “[...] a finalidade é provocar estímulos individuais para que as pessoas, submetidas à insegurança, busquem soluções individuais, exercendo a criatividade e o empreendedorismo. Assim, valoriza-se o mérito individual, com a compreง seu bem-estar".

$\dot{A}$ se contexto, os trabalhadores devem ver a si 今 mesmos como trabalhadores autônomos, responsáveis por investir em si mesmos e vender suas habilidades, tornando-se um bricoler de sua condição de empregabilidade. Para Bila Sorj (2000, p. 32),

[...] a constante incerteza, advinda da pluralidade de formas de contratos de trabalho, em relação à duração, ao tempo e à localização das atividades, asso- ciada à rápida obsolescência das habilidades adquiridas, requerem das pessoas intensos investimentos privados e permanente sintonia com as eventuais oportunidades que o mercado oferece [...]

A empregabilidade, segundo Luiz Antonio Machado da Silva (2002), vem se transformando no coração de uma cultura do trabalho em gestação, e representa o elenco dos atributos subjetivos - disposições pessoais, competências, etc. - que as empresas esperam dos trabalhadores, correspondendo às necessidades de uma produção "flexibilizada". O autor ressalta que, mais do que a aquisição de novas competências técnicas, melhor adaptadas às mudanças do regime produtivo, a noção de empregabilidade contém uma dimensão simbólico-ideológica de convencimento/adesão que interfere sobre a formação da autoimagem e da visão de mundo dos trabalhadores (Silva, 2002, p. 8).

\section{CONSIDERAÇÕES FINAIS}

O setor de desenvolvimento de software, cujas configurações constituem-se bastante afinadas com o discurso neoliberal, é caracterizado, entre outras coisas, pela flexibilidade das formas contratuais, apresentando a tendência de relações de emprego precarizadas. Na pesquisa empírica realizada com trabalhadores e empresários do setor, identificamos a recorrência nessa indústria da contratação de trabalhadores como pessoa jurídica, através de cooperativas de trabalho e ou como "CLT Flex". A proliferação de formas flexíveis de contratação parece decorrer de uma tentativa das empresas de afastar os encargos trabalhistas que incidem sobre a relação de trabalho, aumentando, assim, a competitividade, mas também está relacionada, nessa indústria, à forma como se estrutura o processo produtivo, organizado por projetos. O fenômeno é corroborado, ainda, por uma possível "aderência” ou pela adaptação dos trabalhadores a um novo ethos capitalista, nos termos de Boltanski e Chiapello (2009), cunhados, também, nos discursos das 
atuais formas de gestão, que têm em seu cerne a noção de empregabilidade, pois esses trabalhadores se consideram responsáveis pela sua própria estabilidade e inserção no mercado de trabalho.

Isso sugere que o trabalho de desenvolvimento de software não se distingue de outras formas de trabalho assalariado, mas também incorpora todo o conjunto de formas flexíveis de contratação de trabalho que se configuraram no quadro do capitalismo atual.

A lógica que comanda as relações de trabalho na indústria de software nas empresas pesquisadas de Curitiba e Região, portanto, não difere daquela que rege as relações entre capital e trabalho nos dias atuais para os diversos setores da economia. Ainda que referentes a uma conjuntura específica, dados encontrados em nossa pesquisa empírica parecem suficientes para problematizar as teses sobre o trabalho imaterial quando afirmam que essa forma de produção impulsionaria uma emancipação política do "operário social”, possibilitada pela sua qualificação técnica, levando ao fim da sociedade de classes e da exploração do trabalho pelo capital.

Recebido para publicação em 17 de abril de 2014 Aceito em 08 de setembro de 2014

\section{REFERÊNCIAS}

ANTUNES, Ricardo. Os sentidos do trabalho: ensaio sobre a afirmação e a negação do trabalho. São Paulo: Boitempo, 2009. 264p.

BALTAR, Paulo; KREIN, José Dari; LEONE, Eugenia Troncoso. Economia e mercado de trabalho. In: LEITE, Marcia; ARAUJO, Angela M. C (Orgs.). O trabalho reconfigurado: ensaios sobre o Brasil e México. São Paulo: Annablume, 2009. p. 27-45.

BOLTANSKI, Luc; CHIAPELLO, Éve. O novo espírito do capitalismo. São Paulo: Martins Fontes, 2009.

BRAUNERT, Mariana. O trabalho e as formas de contratação dos desenvolvedores de software: um estudo em empresas de Curitiba e Região. 2013. 155 p. Dissertação (Mestrado em Sociologia) - Programa de Pós-Graduação em Sociologia da Universidade Federal do Paraná.

BRIDI, Maria Aparecida. Redes de empresas, trabalho e relações de trabalho no setor de informática no Paraná. Projeto de Pesquisa. Curitiba: UFPR, 2011a.

O setor de tecnologia da informação: o que há de novo no horizonte do trabalho? Revista de Ciências Sociais - Política \& Trabalho. Programa de Pós-Graduação em Sociologia da UFPB. João Pessoa, n. 41, p. 277-304, Out. de 2014.

; MOTIM, Benilde Lenzi. Trabalho e trabalhadores na indústria de informática. Contemporânea - Revista de Sociologia da UFSCar. São Carlos, v. 4, n. 2, jul-dez 2014, p. 351-380.

CARDOSO, Adalberto Moreira. A década neoliberal e a crise dos sindicatos no Brasil. São Paulo: Boitempo Editorial, 2003. 328p.

COCCO, Giuseppe; VILARIM, Gilan de Oliveira. Trabalho imaterial e produção de software no capitalismo cognitivo. In: Liinc em Revista. Rio de Janeiro, v. 5, n. 2, p. 173-190, set. 2009.

CORIAT, Benjamin. Pensar pelo avesso: o modelo japonês de trabalho e organização. Rio de Janeiro: UFRJ / Revan, 1994. 209p.

CORREIA, Josiane Gutierrez; VASQUEZ, Felipe Ferraz; CARIO, Silvio Antonio Ferraz. Características da estrutura produtiva e padrão de concorrência da indústria de software no Brasil. Textos de Economia. Florianópolis, v. 11, n. 2, p. 108-140, jul./dez. 2008.

DEDECCA, Claudio Salvadori. Flexibilidade e regulação de um mercado de trabalho precário: a experiência brasileira. In: GUIMARÃES, Nadya Araújo; HIRATA, Helena; SUGITA, Kurumi (Org.). Trabalho flexível, empregos precários? Uma comparação Brasil, França, Japão. São Paulo: Editora da USP, 2009. p. 123-142.

DIEGUES JUNIOR, Antonio Carlos. Atividade de software no Brasil: dinâmica concorrencial, política industrial e desenvolvimento. 2010. 284 f. Tese (Doutorado em Ciências Econômicas) - Instituto de Economia da Universidade Estadual de Campinas. 2010.

DRUCK, Graça. Trabalho, precarização e resistências: novos e velhos desafios? Caderno CRH, Salvador: EDUFBA, v. 24, n. spe 1, p. 37-57, 2011.

; FRANCO, Tânia. Terceirização: a chave da precarizacão do trabalho no Brasil. In: NAVARRO, Vera Lucia; PADILHA, Valquíria (Org.). Retratos do trabalho no Brasil. Uberlândia: Edufu, p. 225-254. 2009.

GALEAZZI, Irene; HOLZMANN, Lorena. Precarização do trabalho. In: CATTANI, Antonio David; HOLZMANN Lorena (Orgs.). Dicionário de trabalho e tecnologia. 2. ed. rev. ampl. Porto Alegre: Zouk, 2011. p. 259-265.

HARDT, Michael; NEGRI, Antônio, Multidão: guerra e democracia na era do império. Tradução: Clóvis Marques. Rio de Janeiro: Record, 2005.

HARVEY, David. A condição pós-moderna: uma pesquisa sobre as origens da mudança cultural. 2. ed. São Paulo: Loyola, 1993.

HOLZMANN, Lorena. Fordismo. In: CATTANI, Antonio David; HOLZMANN, Lorena (Orgs.). Dicionário de trabalho e tecnologia. 2. ed. rev. ampl. Porto Alegre: Zouk, 2011. p. 199-203.

; PICCININI, Valmíria. Flexibilização. In: CATTANI, Antonio David; HOLZMANN, Lorena (Orgs.). Dicionário de trabalho e tecnologia. 2. ed. rev. ampl. Porto Alegre: Zouk, 2011. p. 196-199.

KOVÁCS, Ilona. Emprego flexível em Portugal. Sociologias. Porto Alegre, ano 6, n. 12. p. 32-67, jul./dez. 2004.

GORZ, André. O Imaterial: conhecimento, valor e capital. São Paulo: Annablume, 2005. 106p.

KOVÁCS, Ilona. Emprego flexível em Portugal. Sociologias. Porto Alegre, ano 6, n. 12. p. 32-67, jul./dez. 2004

KREIN, José Dari. O aprofundamento da flexibilização das relações de trabalho no Brasil nos anos 90. 2001. $202 \mathrm{f}$. 
Dissertação (Mestrado em Economia social e do trabalho) - Instituto de Economia, Universidade Estadual de Campinas. 2001.

KUBOKA, Luis Claudio. Desafios para a indústria de software. Texto para discussão $n^{\circ}$ 1150. Brasília: IPEA, 2006 .

LAZARATTO, Mauricio; NEGRI, Antònio. Trabalho imaterial: formas de vida e produção de subjetividade. Rio de Janeiro: DP\&A, 2001

NEVES, Magda de Almeida. Trabalho atípico. In: CATTANI, Antonio David; HOLZMANN, Lorena (Orgs.). Dicionário de trabalho e tecnologia. 2. ed. rev. ampl. Porto Alegre: Zouk, 2011.

OLIVEIRA, Daniela Ribeiro de. Os trabalhadores da indústria de software: flexíveis e precários? 2009. 114 f. Dissertação (Mestrado em Sociologia) - Centro de Educação e Ciências Humanas, Universidade Federal de São Carlos, São Carlos, 2009.

OLIVEIRA, Luísa; CARVALHO, Helena. A precarização do emprego na Europa. Dados - Revista de Ciências Sociais, v. 51, n. 3, p. 541-567, 2008.

PEREIRA, Samara Flores Carvalho. A condição do "trabalhador-empresa": um estudo sobre a modalidade de contratação "pessoa jurídica” no segmento de software em Curitiba. 2013. Dissertação (Mestrado em Sociologia) - Programa de Pós-Graduação em Sociologia da Universidade Federal do Paraná.

ROSELINO JUNIOR, José Eduardo. Panorama da indústria brasileira de software: considerações sobre a política industrial. DE NEGRI, J. A.; EKUUBOTA, L. C (Orgs.). Estrutura e dinâmica no setor de serviços no Brasil. Brasília: IPEA, 2006.

SALATTI, Rita de Cássia. Flexibilização do trabalho em empresas de desenvolvimento de sistemas. 2005. $119 \mathrm{f}$

Dissertação (Mestrado em Política Científica e Tecnológica) - Instituto de Geociências, Universidade Estadual de Campinas.

SILVA, Luiz Antonio Machado da. Mudanças no mundo do trabalho: uma nota. Associação de Ciências Sociais e Humanas em Língua Portuguesa. Rio de Janeiro, set. 2002.

SORJ, Bila. Sociologia e trabalho: mutações, encontros e desencontros. Revista Brasileira de Ciências Sociais. São Paulo, v. 15, n. 43, jun. 2000.

SOFTEX. Software e serviços de TI: a indústria brasileira em perspectiva. Observatório SOFTEX. v.1, n. 1. Capinas: 2009

A industria de software no Brasil: fortalecendo a economia do conhecimento. Campinas: SOFTEX, 2003. 
WORK AT THE SOFTWARE INDUSTRY: flexibility a standard in forms of employment

\author{
Maria Aparecida Bridi \\ Mariana Bettega Braunert
}

This study analyzes the flexibility of the forms of employing the workforce of the software developers from the city of Curitiba and its surroundings. It is the result of an empirical research in which we interviewed workers and employers from that sector. We found a predominance of workers being contracted as a legal entity, as "CLT Flex" or through a worker co-operative. Beyond a clear attempt by the companies of getting rid of charges on worker relations, the proliferation of flexible forms of contracting seems related, in that sector, to the way the productive process is structured, organized in projects, and to the discourse that justifies the current forms of management, which have in its center the notion of employability. These findings indicate that labor involving high technology is also organized as a typically capitalist wage work, whose logic does not differ from the one that governs the relations between capital and work in other sectors of the economy.

KEYWORDS: Software industry, work contract, flexibility, forms of management, productive process.

\section{LE TRAVAIL DANS L'INDUSTRIE DU LOGICIEL: la flexibilité comme référence pour les contrats}

\author{
Maria Aparecida Bridi \\ Mariana Bettega Braunert
}

Cette recherche analyse la flexibilité des contrats d'embauche de la force de travail de ceux qui fabriquent des logiciels à Curitiba et dans sa région. C'est l'aboutissement d'une recherche empirique faite grâce à des interviews réalisées auprès des travailleurs et des entrepreneurs de ce secteur. Il en ressort une nette préférence pour des contrats avec ceux qui sont enregistrés comme personnes juridiques, comme "CLT Flex" ou organisés en coopératives de travail. Au-delà du fait que les entreprises essaient très clairement de ne pas avoir à payer les charges sociales obligatoires dans une relation de travail, la prolifération de de contrats en termes de plus en plus flexibles semble être directement liée, dans ce secteur, à la manière dont est structuré le processus productif, organisé par projets, et à un discours justificatif des formes de gestion actuelles au coeur duquel se trouve la notion d'emploi. Ces contrats démontrent que le travail, qui suppose un haut niveau de technologie, est aussi organisé comme un travail salarié typiquement capitaliste et dont la logique ne semble pas être différente de celle qui règle les relations entre le capital et le travail dans d'autres segments de l'économie.

Mots-CLÉs: Industrie des logiciels, contrat de travail, flexibilité, formes de gestion, processus productif.

Maria Aparecida Bridi - Doutora em Sociologia pela Universidade Federal do Paraná. Professora
Universidade Federal do Paraná Diretora executiva da Associação Brasileira de Estudos de Trabalho,
coordenadora do GETS - Trabalho e Sociedade da Universidade Federal do Paraná. Tem experiência na
área de Sociologia, com ênfase em Sociologia do Trabalho, atuando principalmente nos seguintes temas:
trabalho informacional, metalúrgicos, sindicalismo, indústria automobilística, bancários e ação sindical.
Publicações recentes: Trabalho e trabalhadores na indústria de informática. Contemporânea - Revista
de Sociologia da UFSCar, v. 4, p. 351-380, 2014; O setor de tecnologia da informação: o que há de novo
no horizonte do trabalho? Política \& Trabalho (Online), v. 41, p. 277-304, 2014; O trabalho no setor de
informática no Paraná: reflexões sociológicas. Revista Paranaense de Desenvolvimento, v. 34, p. 93-118,
2013.
Mariana Bettega Braunert - Doutoranda em Sociologia do Programa de Pós Graduação em Sociologia
(PPGS) da Universidade Federal do Paraná. Tem experiência na área de Sociologia, com ênfase em
Ciência Política e Sociologia do Trabalho, atuando principalmente nos seguintes temas: elites políticas,
contratação flexível, indústria de software e formas de gestão de trabalho no setor público. Publicações
recentes: Direitos Humanos, racismo e seu disciplinamento no ordenamento jurídico brasileiro. Revista
Bonijuris, v. 560, p. XX-XXV, 2010; Trabalho e fé: uma análise jurídica da natureza dos serviços prestados
a instituições religiosas. Revista Bonijuris, v. 20, p. 12-15, 2008; A direita, a esquerda e a democracia: os
valores políticos dos parlamentares paranaenses (1995-2002). Opinião Pública (UNICAMP), Campinas,
v. 12, n.1, p. 114-135, 2006 
